\title{
Net Carbon Gain and Growth of Bell Peppers, Capsicum annuum 'Cubico', Following Root Infection by Pythium aphanidermatum
}

\author{
M. Johnstone, S. Chatterton, J. C. Sutton, and B. Grodzinski
}

First and fourth authors: Department of Plant Agriculture, University of Guelph, Guelph, ON, Canada, N1G 2W1; second author: Department of Biological Sciences, Simon Fraser University, 8888 University Drive, Burnaby, BC, Canada, V5A1S6; and third author: Department of Environmental Biology, University of Guelph, Guelph, ON, Canada, N1G 2 W1.

Accepted for publication 6 December 2004.

\begin{abstract}
Johnstone, M., Chatterton, S., Sutton, J. C., and Grodzinski, B. 2005. Net carbon gain and growth of bell peppers, Capsicum annuum 'Cubico', following root infection by Pythium aphanidermatum. Phytopathology 95:354-361.

The first characterization of alterations in whole-plant photosynthetic rate and carbon assimilation of bell peppers associated with infection by Pythium aphanidermatum is described. Relationships of root disease caused by $P$. aphanidermatum to whole-plant net carbon exchange rate (NCER), total carbon accumulation, dark respiration rates, water loss, and destructive growth parameters were quantified in vegetative, hydroponically grown pepper plants (Capsicum annиum 'Cubico'). Inoculated plants displayed lower whole-plant NCER. This translated into a loss of

$28 \%$ in cumulative $\mathrm{C}$ gain during 7 days after inoculation and occurred before visible shoot symptoms developed. Leaf area and dry weight of shoots and roots were significantly decreased and the shoot/root ratio was higher in inoculated plants than in noninoculated plants. We propose that reduced NCER in inoculated plants was mainly due to restricted development of leaf area, because no differences in NCER and evapotranspiration were observed between control and inoculated plants when expressed based on leaf area and root dry mass, respectively. These findings indicate that Pythium infection did not affect the photosynthetic apparatus directly and that the reductions in photosynthesis and growth were not caused by inefficient water transport by diseased roots. These results enlarge on the understanding of physiological responses of host plants to early stages of root disease.
\end{abstract}

Pythium aphanidermatum (Edson) Fitzp. is a principal pathogen contributing to root rot of bell pepper (Capsicum annuum L.) and other hydroponic greenhouse crops $(4,28,39,45)$. P aphanidermatum is worldwide in distribution and can enter water supplies and nutrient solutions by many means, including dust deposited on greenhouse roofs (35). In hydroponic systems, roots, root exudates, and circulating nutrient solution provide a favorable environment for growth, reproduction, and dispersal of $P$. aphanidermatum, which is dispersed as zoospores or as hyphae on fragments of diseased roots $(29,45)$. Infected roots develop tip necrosis, expansive browning, and decay. Relationships of root rot epidemics to shoot growth and fruit development, however, are poorly understood.

Epidemics of root rot usually progress rapidly in hydroponic pepper crops and increase in severity over several months (28). Symptoms on aerial portions of the crop often include stunted shoots and smaller, fewer fruits. When root rot is severe, and especially when air and/or nutrient solution temperatures are high, the foliage may wilt and the plants may die within a few days $(20,28)$. The leaf canopy generally remains green until advanced stages of wilting. Root rot affects host growth and reproduction long before visible symptoms such as wilting or chlorosis on aerial portions of the plants become noticeable.

The relationship of root disease caused by $P$. aphanidermatum and growth in hydroponic peppers is currently understood chiefly from investigations in small-scale hydroponic systems. When applied as zoospore suspensions to roots of vegetative-stage pepper plants grown in single-plant hydroponic containers or in trough systems containing five to seven plants, the pathogen reduced the

Corresponding author: B. Grodzinski; E-mail address: bgrodzin@uoguelph.ca

DOI: 10.1094/PHYTO-95-0354

C) 2005 The American Phytopathological Society volume, fresh mass, total length and surface area of the roots, as well as total leaf area, and shoot height and fresh mass over 2 to 3 weeks following inoculation $(23,28)$. Reductions in root and shoot dry mass were observed in plants grown in trough systems (23). No significant change in chlorophyll content in leaves was encountered in these investigations. $P$. aphanidermatum rapidly colonized a majority of the roots, but incidence of root browning increased at widely differing rates that were related to temperature and other environmental variables (29). While plant growth is generally reduced after roots are infected and colonized by rootrotting pathogens including $P$. aphanidermatum, the changes in physiological processes that mediate yield reduction are not well understood, whether in hydroponic systems or soils.

Growth and productivity at the whole plant level depend on photosynthesis and respiration (22). To date, most studies of these variables in diseased plants have focused on gas exchange in single leaves of infected plants compared with control plants. Changes in leaf photosynthesis and transpiration associated with stomatal closure were recognized as early foliar responses to rootinfecting pathogens $(3,31)$. In bell peppers inoculated at the stem with Phytophthora capsici, leaf photosynthesis and conductance were significantly reduced 4 days after inoculation (DAI), coupled to a rise in dark respiration and ethylene production (1). Net $\mathrm{CO}_{2}$ assimilation in leaves of young avocado plants was reduced 7 days after the plants were transplanted into soil infested with Phytophthora cinnamomi, and by $75 \%$ at 14 days (31). Reductions in assimilation, stomatal conductance, and transpiration preceded development of visible shoot symptoms, chiefly wilting and defoliation, by several days. Similar responses and reductions in leaf photosynthesis were reported for the vascular wilt pathogens Verticillium or Fusarium in tomato $(10,26)$, potato $(5-7,18)$, pepper (16), chrysanthemum (17,27), and alfalfa (30). One study of the relationship between photosynthesis and disease, however, examined eggplants infected by $V$. dahliae on a whole-plant basis. 
Plants grown in Verticillium-infested soil had a lower whole-plant photosynthetic rate than did the controls (14). The reduced canopy photosynthesis was attributed to the reduced leaf area due to defoliation of infected plants. Defoliation is a clear and severe loss of photosynthetic capacity of a plant canopy. In more sublethal situations, the canopy does not show such visible changes, but photosynthetic capacity may be altered by drooping of the leaves, presentation of the leaves to the light source, or by actual alterations in the photosynthetic rate due to chemical signals transported to the leaves. Regardless of the mechanism, it is of fundamental importance to develop an understanding of how root disease affects, both directly and indirectly, processes that influence net carbon gain and thus productivity in whole plants.

In the present study, whole-plant development was studied in vegetative-stage pepper plants grown in single-plant hydroponic units by quantifying growth of the leaf canopy and roots. Concomitantly, water loss and net carbon exchange rates (NCER) throughout photoperiods and dark cycles were measured continuously. Total daily carbon accumulation and host growth parameters were quantified after plants were inoculated with $P$. aphanidermatum. There were three main objectives of these experiments. The first was to determine the relationships between root disease caused by $P$. aphanidermatum and changes in host plant productivity. The second was to use day and night (diel) gas exchange measurements of the whole plants as a means for noninvasive measurement of crop growth during the onset and progression of root rot. The third was to test whether gas exchange $\left(\mathrm{CO}_{2}\right.$ and/or $\mathrm{H}_{2} \mathrm{O}$ ) could be used to predict the onset of infection and disease. Taken together, these data would allow use of the plant as a primary sensor of its health status in early stages of root rot epidemics.

\section{MATERIALS AND METHODS}

Plant material and growth conditions. Seeds of $C$. annuum cv. Cubico (De Ruiter Seed Co., Columbus, $\mathrm{OH}$ ) were germinated on filter paper for 5 days and transferred to small rockwool cubes (Grodan Group, Roermond, The Netherlands). After 4 weeks, the seedlings were transplanted to $475-\mathrm{ml}$ plastic containers (Fisher Scientific, Ottawa, ON) filled with nutrient solution $(0.83 \mathrm{~g}$ of Plant Prod 7-11-27 N:P:K supplemented with $0.57 \mathrm{~g}$ of $\mathrm{CaNO}_{3}$ per liter, Plant Products Ltd., Brampton, ON), pH 5.8 and electrical conductivity (EC) $1.8 \mathrm{mS} / \mathrm{cm}$, and aerated with aquarium pumps (Maxima, Rolf C. Hagen Inc., Montreal, QC). The solution was topped up manually at intervals of 1 to 2 days, when conductivity was also checked. Plants were grown in growth chambers (Conviron, Winnipeg, MB) at $27 \pm 0.1^{\circ} \mathrm{C}$ (day) and $24 \pm$ $0.1^{\circ} \mathrm{C}$ (night), with an ambient $\mathrm{CO}_{2}$ concentration of $365 \mu \mathrm{l} /$ liter and relative humidity $(\mathrm{RH})$ of $50 \pm 5 \%$ at an initial planting density of 58 plants per $\mathrm{m}^{2}$. The light source was a combination of fluorescent lamps (Cool White $115 \mathrm{~W}$, GTE Sylvania Canada Ltd.) and incandescent bulbs (Cool White $60 \mathrm{~W}$, GTE Sylvania Canada Ltd.) that provided approximately $400 \mu \mathrm{mol} / \mathrm{m}^{2} / \mathrm{s}$ of photosynthetically active radiation (PAR) at canopy height during 16-h photoperiods.

Pythium inoculation protocol. Zoospores of $P$. aphanidermatum isolate P6 (29) were produced by a method similar to that of Rahimian and Banihashemi (32). The isolate was grown on V8juice agar medium in petri dishes at $25^{\circ} \mathrm{C}$ for $48 \mathrm{~h}$, after which the medium was cut into six 1-cm-wide strips. Alternate strips in each dish were transferred to an empty petri dish, and all dishes were flooded with $25 \mathrm{ml}$ of sterile distilled water. The plates were incubated at $25^{\circ} \mathrm{C}$ under fluorescent lights, and after $48 \mathrm{~h}$, the water was replaced with another $25 \mathrm{ml}$ of sterile distilled water. After incubation at $20^{\circ} \mathrm{C}$ under fluorescent lighting for $4 \mathrm{~h}$ to stimulate zoospore release, zoospore suspensions were collected and zoospore density was estimated with a hemacytometer as described previously (29). Plants were inoculated 14 days after trans- planting by immersing the root systems in suspensions of $6.25 \times$ $10^{3}$ zoospores per $\mathrm{ml}$ of sterile water for $30 \mathrm{~min}$. Roots of control plants were immersed in sterile water for $30 \mathrm{~min}$.

Evaluation of colonization and disease. Roots were visually assessed for percent incidence of discolored roots and percent incidence of brown root tips at $24 \mathrm{~h}$ after inoculation, and at 48 -h intervals thereafter using separate incremental scales as follows: $0=0 \%, 1=1$ to $10 \%, 2=11$ to $20 \% \ldots$, and $10=91$ to $100 \%$. The incidence of roots colonized by $P$. aphanidermatum from inoculated and control plants was estimated at $24 \mathrm{~h}$ after inoculation, and at $48 \mathrm{~h}$ intervals thereafter. At each time of sampling, 10-cmlong distal portions of each of three primary roots per plant were cut off and the laterals were removed with a sterile scalpel. For surface disinfestations, roots were immersed in $50 \%$ ethanol for $10 \mathrm{~s}$ and in $1 \% \mathrm{NaOCl}$ for $30 \mathrm{~s}$, rinsed three times in sterile distilled water, and then blotted dry. Each root was cut into $101-\mathrm{cm}-$ long segments and the segments were placed on a Pythium-selective medium $\left(\mathrm{P}_{5} \mathrm{ARP}\right.$ agar medium [21]) in petri dishes. Incidence of root pieces with Pythium colonies was estimated after $24 \mathrm{~h}$ and the plates were examined at $72 \mathrm{~h}$ for incidental fungi.

Destructive plant growth analysis. Six plants of each treatment were randomly selected for destructive harvest at 48-h intervals starting 1 day prior to inoculation until 7 DAI. Leaf area was measured with a belt meter (LI-3000, LI-COR, Lincoln, NE). Fresh mass of leaves, stems, and roots was measured immediately after harvesting. These tissues were then dried at $75^{\circ} \mathrm{C}$ for $48 \mathrm{~h}$ prior to dry weight determination.

Nondestructive plant growth analysis. Biomass gain was determined from analysis of daytime and nighttime whole-plant net $\mathrm{CO}_{2}$ gas exchange, measured as described by Dutton et al. (11) and modified by Leonardos et al. (25). Ten days after transplanting, pepper plants were transferred from the growth cabinet to sealed gas analysis chambers with computer-controlled temperature $\left(27^{\circ} \mathrm{C}\right.$ day $/ 24^{\circ} \mathrm{C}$ night $)$, humidity $(45 \% \mathrm{RH})$, and $\mathrm{CO}_{2}$ concentration $(365 \mu \mathrm{l} /$ liter $)$. Four plants were positioned so as to minimize mutual shading in each of four separate chambers. High pressure sodium lamps (1,000 W, Lumalux LU 1,000; GTE Sylvania Canada Ltd.) provided PAR (400 to $700 \mathrm{~nm}$ ) at $400 \mu \mathrm{mol} / \mathrm{m}^{2} / \mathrm{s}$ as measured by quantum sensors (Q3991-4; LI-COR) at the top of the plant canopy.

Transpiration of the whole plants was also determined continuously. Inside the sealed chambers, pots were placed on an analytical balance (PG8001-S, Mettler Toledo, Columbus, OH) with measurements recorded at 4-min intervals (BalanceTalk XL, Labtronics Inc., Guelph, ON) to estimate whole-plant water loss by evapotranspiration. Nutrient solution was added daily as needed, without opening the chambers, with a gravity-controlled line feed from an external overhead reservoir. The nutrient solution in each container was aerated with air from within the gas analysis chamber. Evaporation from the nutrient solution during aeration was accounted for by subtracting values for control runs (i.e., containers with no plants) from the cumulative water loss data of those with plants.

NCER was measured continuously for 10 days commencing with the daylight period following an overnight equilibration of $12 \mathrm{~h}$; chambers were opened and the plants were removed for inoculation on the third full day, allowing 7 days of postinoculation measurements. NCER was calculated from initial and final $\mathrm{CO}_{2}$ concentrations in the chamber atmosphere and pure $\mathrm{CO}_{2}$ injection measurements every $6 \mathrm{~min}$ in a manner described previously (25). Carbon accumulation was calculated by integrating NCER over the measurement period. Statistical significance of total carbon accumulation was assessed by one-way analysis of variance (SPlus 2000, Insightful Corporation, Seattle, WA).

In order to express plant $\mathrm{CO}_{2}$ and $\mathrm{H}_{2} \mathrm{O}$ gas exchange on a unit biomass basis, the leaf area of the plant canopy in each chamber was measured destructively at the end of the 10-day $\mathrm{CO}_{2}$ measurements. Dry weights of leaf, stem, and root tissues were 
also determined as described. Leaf area and dry matter changes of plants in the NCER chambers were approximated from predicted values generated from regressions fitted to data from destructive harvests of plants grown concurrently under similar environmental conditions in growth cabinets. Percent roots discolored and percent colonized by $P$. aphanidermatum were also estimated.

Apparent quantum yield. Apparent quantum yield (AQY) was defined as the ratio between mole $\mathrm{CO}_{2}$ fixed $/ \mathrm{mole}$ photons incident on the canopy within the whole-plant gas exchange chambers (42). This determination of canopy photosynthetic efficiency utilizing the total leaf area within the chamber is a modification to the QY method, as discussed by Bugbee and Monje (8). While Bugbee and Monje (8) used the QY approach when discussing the theoretical limits to crop productivity, they presented an empirical function of absorbed photon flux for a wheat canopy. In the ab-

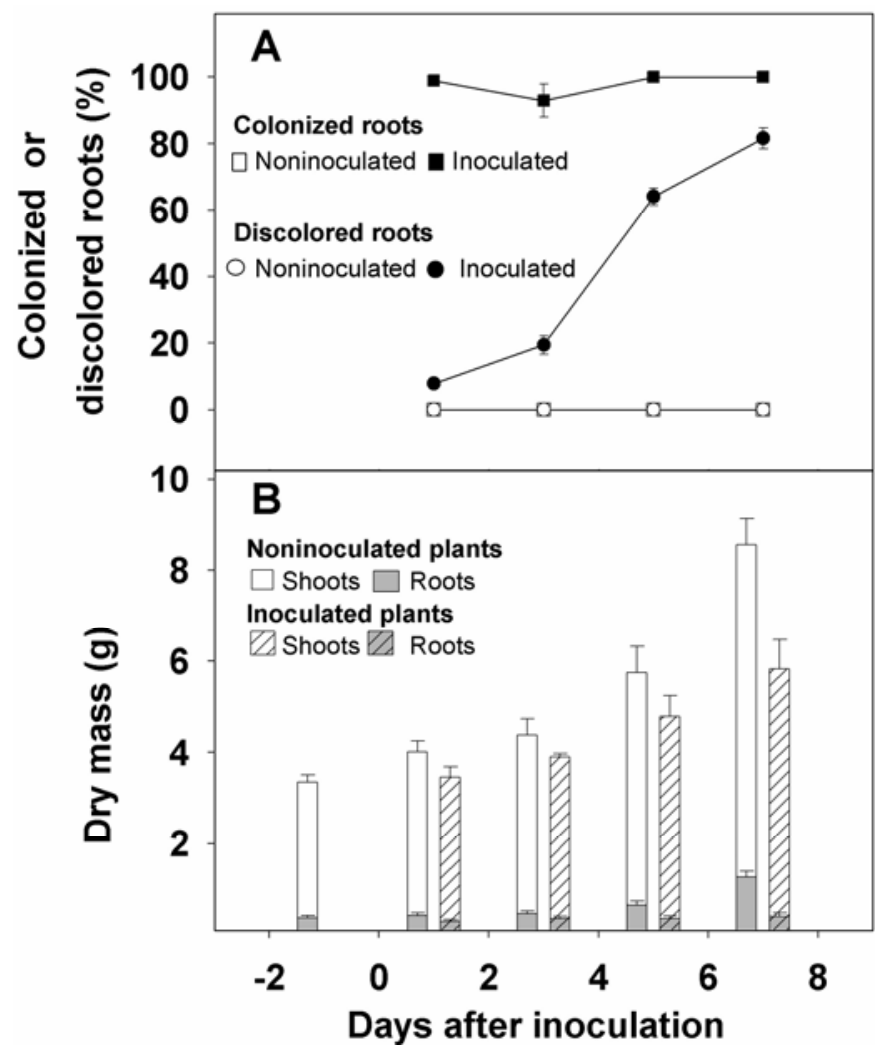

Fig. 1. A, Disease progress in roots and B, dry mass measurements of shoots and roots of hydroponic pepper plants following inoculation with Pythium aphanidermatum. Each data point and histobar represents the mean \pm SE for a minimum of six plants. The experiment was repeated four times with similar results for similar inoculum density and vigor; results from one representative experiment are shown. sence of empirical measurements of light absorption by the plants in each chamber, a more conservative estimate is proposed as the AQY. The term apparent is applied here to distinguish between determinations of photosynthetic efficiency based on incident (AQY) or absorbed (QY) radiation.

\section{RESULTS}

Growth inhibition accompanying root discoloration. Root discoloration (chiefly browning) increased rapidly and exceeded $80 \%$ by 7 DAI in the inoculated plants, whereas all roots of noninoculated control plants remained white (Fig. 1A). Colonization incidence by $P$. aphanidermatum of root segments of inoculated plants was high (95 to 100\%) at all sampling times, but the pathogen was not recovered from the controls. Following conventional destructive harvesting, dry mass estimates of the shoots and roots were significantly lower in the inoculated plants compared with those in the control plants at $5 \mathrm{DAI}$ ( $t$ test, $P=0.0001$ ), and were 32 and $69 \%$ lower, respectively, at 7 DAI (Fig. 1B). The progressive suppression of shoot and root dry mass in the inoculated plants roughly paralleled the increase in percent discolored roots. Roots of control plants grew continuously during the experiment (Table 1), whereas in the inoculated plants, the length of the longest root decreased over time. Root regeneration was not observed in the inoculated plants.

Data of the destructive harvests indicated that by 5 DAI, shoot/root ratios were significantly greater, and shoot fresh mass, length of the longest root, and total leaf area were significantly lower in the inoculated plants compared with the control plants (Table 1). These differences increased by 7 DAI. At 7 DAI, total leaf area was $41 \%$ lower in the inoculated plants than in noninoculated controls. The changes in both root growth and leaf canopy development following inoculation with $P$. aphanidermatum are important in understanding changes in the primary physiological behavior of the host plants.

Nondestructive estimations of whole-plant water loss. On a per plant basis, transpiration rates of control plants were not significantly different from those of inoculated plants for at least 5 days, at which time the larger control plants lost more water (Fig. 2A). However, when water loss from the canopy was expressed on a leaf area basis, there was no difference between control and inoculated plants throughout the entire experiment (Fig. 2B). Taken together, Figure 2A and B clearly indicate that any differences in the absolute amount of water lost by inoculated and control plants were probably related to the larger, more rapidly expanding leaf canopy of the control plants (Table 1).

To provide a crude estimate of the effect of any disease in the root systems inoculated with $P$. aphanidermatum on the capacity of the host plants for water uptake via the transpiration stream, transpiration rates were also expressed on a root mass basis (Fig. $2 \mathrm{C})$. According to these calculations, the inoculated plants tran-

TABLE 1. Destructive harvest measurements of hydroponic pepper plants following inoculation with Pythium aphanidermatum ${ }^{\mathrm{y}}$

\begin{tabular}{|c|c|c|c|c|c|}
\hline Days after inoculation & Treatment & Shoot/root ratio ${ }^{z}$ & Shoot fresh mass $(\mathrm{g})$ & Length of longest root $(\mathrm{cm})$ & Leaf area $\left(\mathrm{cm}^{2}\right)$ \\
\hline-1 & Control & 9.7 & $40.9 \pm 1.4$ & $27.8 \pm 1.6$ & $948.9 \pm 17.2$ \\
\hline 1 & $\begin{array}{l}\text { Control } \\
\text { Pythium }\end{array}$ & $\begin{array}{l}10.0 \mathrm{a} \\
12.8 \mathrm{a}\end{array}$ & $\begin{array}{l}47.7 \pm 2.6 \mathrm{a} \\
41.8 \pm 1.7 \mathrm{a}\end{array}$ & $\begin{array}{l}26.8 \pm 2.0 \mathrm{a} \\
26.8 \pm 3.2 \mathrm{a}\end{array}$ & $\begin{array}{r}1,106.3 \pm 65.0 \mathrm{a} \\
988.2 \pm 32.2 \mathrm{a}\end{array}$ \\
\hline 3 & $\begin{array}{l}\text { Control } \\
\text { Pythium }\end{array}$ & $\begin{array}{r}9.7 \mathrm{a} \\
11.3 \mathrm{a}\end{array}$ & $\begin{array}{l}52.5 \pm 4.2 \mathrm{a} \\
44.2 \pm 1.2 \mathrm{a}\end{array}$ & $\begin{array}{l}27.8 \pm 2.1 \mathrm{a} \\
26.1 \pm 2.1 \mathrm{a}\end{array}$ & $\begin{array}{l}1,212.0 \pm 94.1 \mathrm{a} \\
1,051.5 \pm 24.8 \mathrm{a}\end{array}$ \\
\hline 5 & $\begin{array}{l}\text { Control } \\
\text { Pythium }\end{array}$ & $\begin{array}{r}9.2 \mathrm{a} \\
14.9 \mathrm{~b}\end{array}$ & $\begin{array}{l}61.5 \pm 5.4 \mathrm{a} \\
48.7 \pm 4.0 \mathrm{~b}\end{array}$ & $\begin{array}{l}27.7 \pm 1.9 \mathrm{a} \\
21.0 \pm 1.6 \mathrm{~b}\end{array}$ & $\begin{array}{l}1,400.7 \pm 139.4 \mathrm{a} \\
1,128.2 \pm 90.6 \mathrm{~b}\end{array}$ \\
\hline 7 & $\begin{array}{l}\text { Control } \\
\text { Pythium }\end{array}$ & $\begin{array}{r}7.1 \mathrm{a} \\
16.7 \mathrm{~b}\end{array}$ & $\begin{array}{l}88.9 \pm 4.4 \mathrm{a} \\
50.1 \pm 5.3 \mathrm{~b}\end{array}$ & $\begin{array}{l}30.3 \pm 0.4 \mathrm{a} \\
20.8 \pm 2.8 \mathrm{~b}\end{array}$ & $\begin{array}{l}1,926.3 \pm 86.1 \mathrm{a} \\
1,131.3 \pm 121.2 \mathrm{~b}\end{array}$ \\
\hline
\end{tabular}

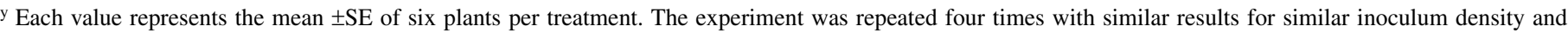
vigor; results from one representative experiment are shown. Values followed by different letters within each day indicate statistical significance using general linear models least square means at $\propto=0.05$.

z Shoot/root ratio values were calculated from dry mass measurements presented in Figure 1.
} 
spired more water than did the healthy controls (Fig. 2C). This trend became apparent as early as $2 \mathrm{DAI}$, indicating that despite any root decay associated with discoloration (Fig. 1A) and reduced root length (Table 1), roots and xylem columns of the inoculated pepper plants remained functional with respect to water uptake and movement of water from roots to shoots.

Nondestructive estimations of whole-plant productivity following inoculation with $P$. aphanidermatum. On a per plant basis, within 3 DAI, photosynthetic rates (NCER in the light) of inoculated plants were lower than those of the controls ( $t$ test, $P=$ $0.0001)$ (Fig. 3A). No significant difference was observed ( $t$ test, $P=0.05)$ in whole-plant dark respiration rate on a plant basis until 7 DAI ( $t$ test, $P=0.0001$ ).

When the $\mathrm{CO}_{2}$ exchange rates were recalculated to show total $\mathrm{C}$ accumulation with time (Fig. 3B), it was clear that inoculated plants were growing more slowly than the controls largely due to the differences in the photosynthetic uptake of $\mathrm{C}$ during the photoperiod. By 7 DAI, the healthy control plants accumulated $28 \%$ more biomass than the inoculated plants did (Fig. 3B), which was consistent with data obtained following destructive harvest and measurement of dry mass (Table 1).

Expression of $\mathrm{CO}_{2}$ exchange rates on a leaf area basis provides an estimate of photosynthesis per unit surface area of leaf canopy available for light interception. No differences in NCER were observed between control and inoculated plants, indicating that the photosynthetic machinery of the infected plants was as efficient on a leaf area basis as that of control plants (Fig. 3C). There was no difference in whole-plant dark respiration rate on a leaf area basis until 7 DAI ( $t$ test, $P=0.0001$ ). When $C$ accumulation was calculated on a leaf area basis, there was no difference in the diel pattern of $\mathrm{C}$ gain and loss during the light and dark periods ( $t$ test, $P=0.05$ ) (Fig. 3D).

Growth of plants is often expressed on a dry weight basis. When NCER and daily $\mathrm{C}$ gain were expressed on a shoot dry mass basis (data not shown), there were no significant differences between the photosynthetic rates and relative growth rates of control and inoculated plants. The pattern of growth on a mass basis was essentially that described previously when calculated on a leaf area basis ( $t$ test, $P=0.0001$ ).

Predicting changes in plant productivity determined noninvasively. Figure 4 shows correlations between root discoloration with NCER (Fig. 4A), whole-plant dark respiration rate (Fig. 4B), and carbon accumulation (Fig. 4C) expressed on a leaf area and per plant basis. Whole-plant dark respiration was not correlated with root discoloration by $P$. aphanidermatum, but photosynthesis and daily $\mathrm{C}$ gain were correlated with root discoloration ( $t$ test, $P=0.0001)$.

Figure 5 illustrates clearly that when AQY was plotted against time, the photosynthetic efficiency of the whole canopy of the control plants was greater than that of the infected plants. Based on the best line fit through the data of all experiments, differences in canopy efficiency between control and infected plants occurred $1 \mathrm{DAI}(t$ test, $P=0.0001)$.

\section{DISCUSSION}

Monitoring responses of host plants inoculated with $\boldsymbol{P}$. aphanidermatum. It is difficult to accurately detect the onset or monitor the progression of root diseases such as Pythium root rot in commercial environments, especially in crops with high plant densities, dense canopies, and reduced accessibility of roots to direct observation. Disease can go undetected when all plants in a cohort are similarly stunted and not exhibiting wilting, chlorosis, or noticeable defoliation $(28,39)$. Disease symptoms such as visible root discoloration and inhibition of root growth in our small-scale hydroponic system (Fig. 1A) were similar to those previously published for hydroponic pepper plants (29). The expansive root browning caused by $P$. aphanidermatum in hydro- ponically grown peppers agrees with earlier findings for this pathogen in pepper plants grown in sterilized soil (9).

Measuring changes in plant dry weight over time have traditionally provided the raw data to assess plant growth under different conditions, but these analyses require repetitive destructive sampling (12). Destructive analyses of plant growth and development can be enhanced greatly when additional parameters such as $\mathrm{CO}_{2}$ gas exchange can be quantified noninvasively each day in whole plants (22). What is new from our studies on P. aphanidermatum are the results correlating changes in whole-plant transpiration, photosynthesis, respiration, and day and night growth patterns that were measured continuously during the first week following inoculation of the pepper plants. These data reveal changes in the primary plant productivity that were not previously documented in any host species infected with $P$. aphanidermatum or other Pythium spp.

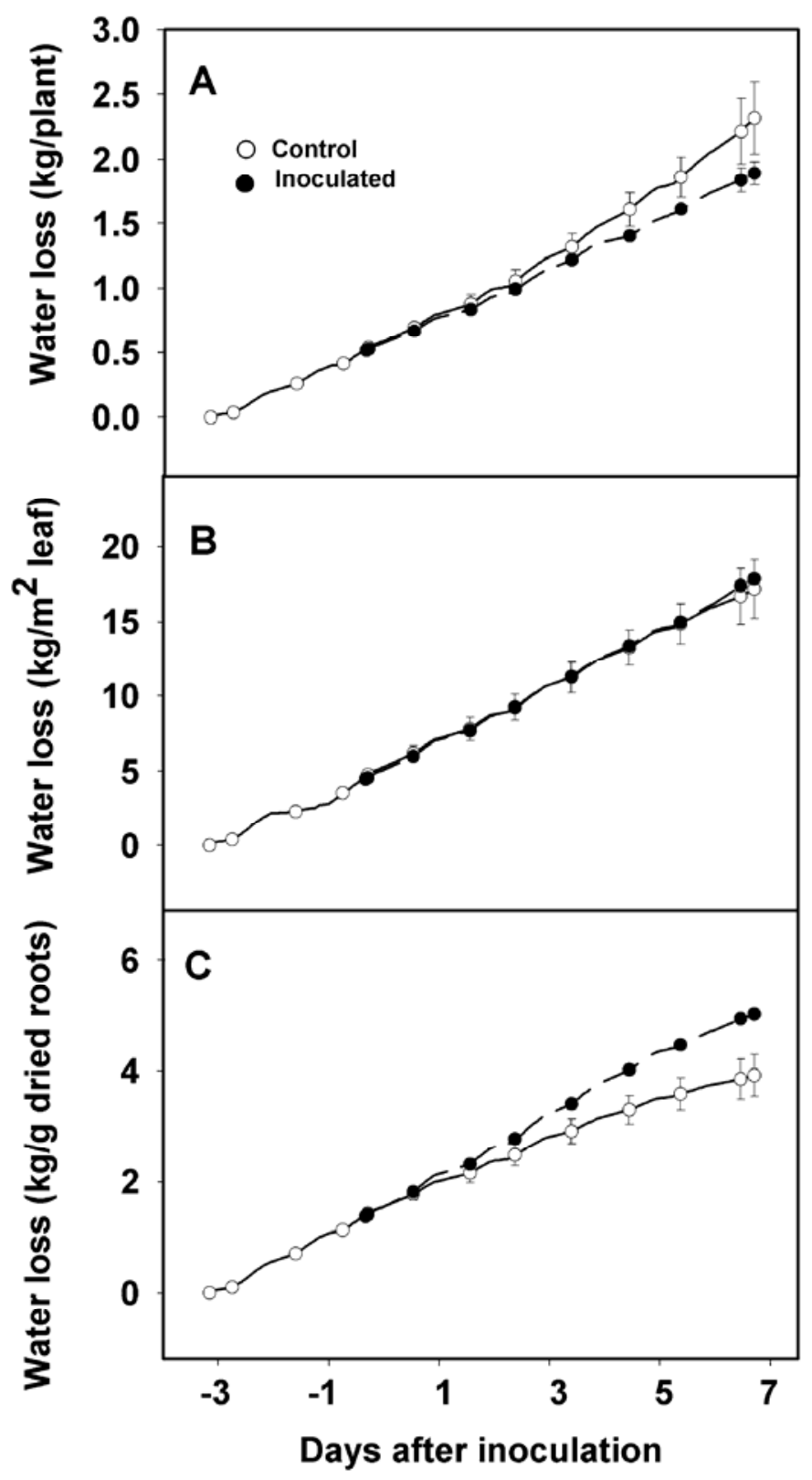

Fig. 2. Cumulative water loss via evapotranspiration in hydroponic pepper plants inoculated with Pythium aphanidermatum compared with that of control plants expressed A, per plant, $\mathbf{B}$, per square meter of leaf area driving transpiration, and $\mathbf{C}$, per gram of dried roots driving uptake. Each value is a mean $\pm \mathrm{SE}$ of four plants in each of two gas exchange chambers. The experiment was repeated four times with similar results for similar inoculum density and vigor; results from one representative experiment are shown. 
The manner in which infection of roots by $P$. aphanidermatum alters gas exchange of pepper plants deserves consideration because the leaf canopy is the source of all assimilates for plant growth. However, the leaf canopy is a heterogeneous structure and clearly remote from the sites of infection and disease development in the roots. One explanation for the apparent drop in the photosynthetic capacity observed on a whole-plant basis (Fig. $3 \mathrm{~A}$ and $\mathrm{B}$ ), but not on the basis of leaf area (Fig. 3C and D) or biomass (data not shown), is the possibility that somehow $P$. aphanidermatum indirectly altered the architecture of the canopy. Alternatively, water stress may have occurred causing stomata to close. Toxins or phytohormones originating in the infected root systems might have affected leaf metabolism (respiration or photosynthesis) and altered leaf growth and expansion.

In the case of wilting or water stress, differences in stomatal behavior and in the presentation of the leaf canopy can occur, thereby changing the ability of leaves to trap light energy, assimilate $\mathrm{CO}_{2}$, and partition photoassimilates to developing sinks. For example, a difference in orientation of leaves of infected plants can be subtle and not easily distinguished by destructive analyses alone, but the impact on canopy photosynthesis and on plant growth rate can be dramatic (43). However, in our studies with pepper plants inoculated with $P$. aphanidermatum, when the drop in NCER and $\mathrm{C}$ gain were first observed (Fig. 3A and B, respectively; Fig. 5), no early sign of wilting, epinasty, or other canopy symptoms were visible and no difference was found in chlorophyll $\mathrm{a} / \mathrm{b}$ content of the infected plants compared with control plants (unpublished data). Interestingly, plant NCER (Fig. 3A) appeared to be altered before changes in transpiration (Fig. 2A) were observed. While some stomatal limitations to $\mathrm{CO}_{2}$ uptake were possible within certain leaves in the canopy, taken together, the whole-plant $\mathrm{CO}_{2}$ (Fig. 3) and $\mathrm{H}_{2} \mathrm{O}$ (Fig. 2) exchange data indicated that any cortical or vascular occlusions that might have resulted following inoculation with $P$. aphanidermatum, and reported in roots infected with other Pythium spp. (Stanghellini and Kronland [39] and references therein), were not a primary cause of reduced $\mathrm{C}$ fixation and growth inhibition.

We favor an alternative explanation for the differences in plant photosynthesis and biomass growth that were observed on a whole-plant basis (Figs. 2A and B, 3A and B, and 5), yet not seen on a leaf area (Fig. 3C and D) or biomass basis. The data are consistent with the conclusion that the lower rates of whole-plant photosynthesis in the infected plants are attributable to reduced development of the leaf canopy rather than to reduced photosynthesis per unit leaf area. The physically smaller leaf canopy of infected plants compared with control plants (Table 1) provided less leaf area to intercept light energy, and thus reduced $\mathrm{C}$ fixation to support growth (Fig. 5).

After assessment of numerous studies on other root diseases $(1,5-7,15,16,18,26,30,31,34)$, it is concluded that our results with $P$. aphanidermatum in peppers are most similar to those for eggplant grown in Verticillium-infested soil (14). In eggplant, when photosynthetic and transpiration rates were expressed on a leaf area basis, there were no significant differences between treatments, supporting the conclusion that yield reductions associated with $V$. dahliae resulted from reduced leaf area instead of reduced photosynthetic efficiency per se.

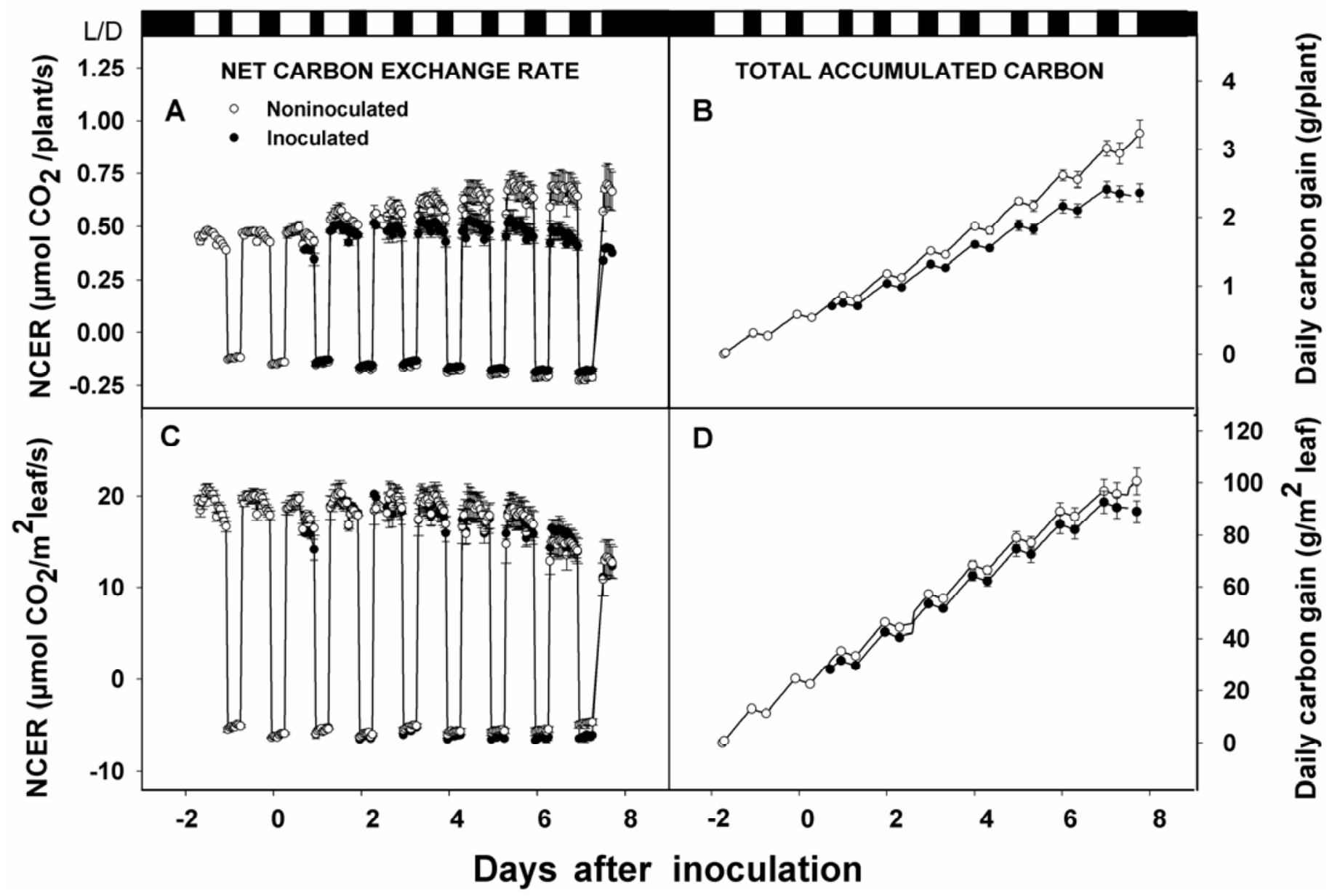

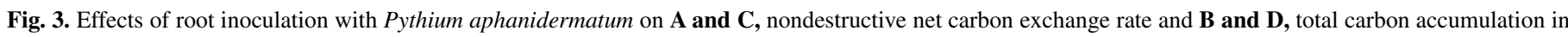

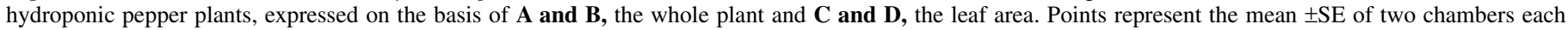

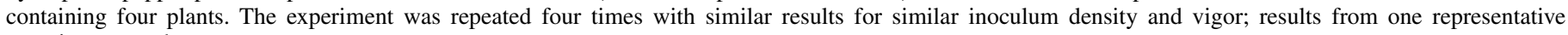
experiment are shown. 
Why would leaf development be altered during root infection by $\boldsymbol{P}$. aphanidermatum? An explanation for reduced leaf development can easily involve any one of the following factors or a combination of several factors including: (i) a limitation on the supply of water for leaf expansion, (ii) a chemical inhibition originating from the root zone, and (iii) an increased competition by the root zone for essential nutrients and photoassimilates that would deprive young developing leaves of essential nutrients for normal development.

The finding that transpiration expressed in absolute terms per plant was reduced only minimally in plants inoculated with $P$. aphanidermatum indicates that events in pathogenesis, such as possible cortical or vascular occlusion, were not a major factor limiting the availability of water for leaf expansion. When expressed per unit root mass, transpiration was actually greater in the inoculated plants compared with the controls (Fig. 2C). Thus, it appears that loss of root integrity associated with intense colonization by the pathogen and progressive discoloration did not significantly reduce water uptake by the plant. Because these observations did not support the view that the leaf canopy was

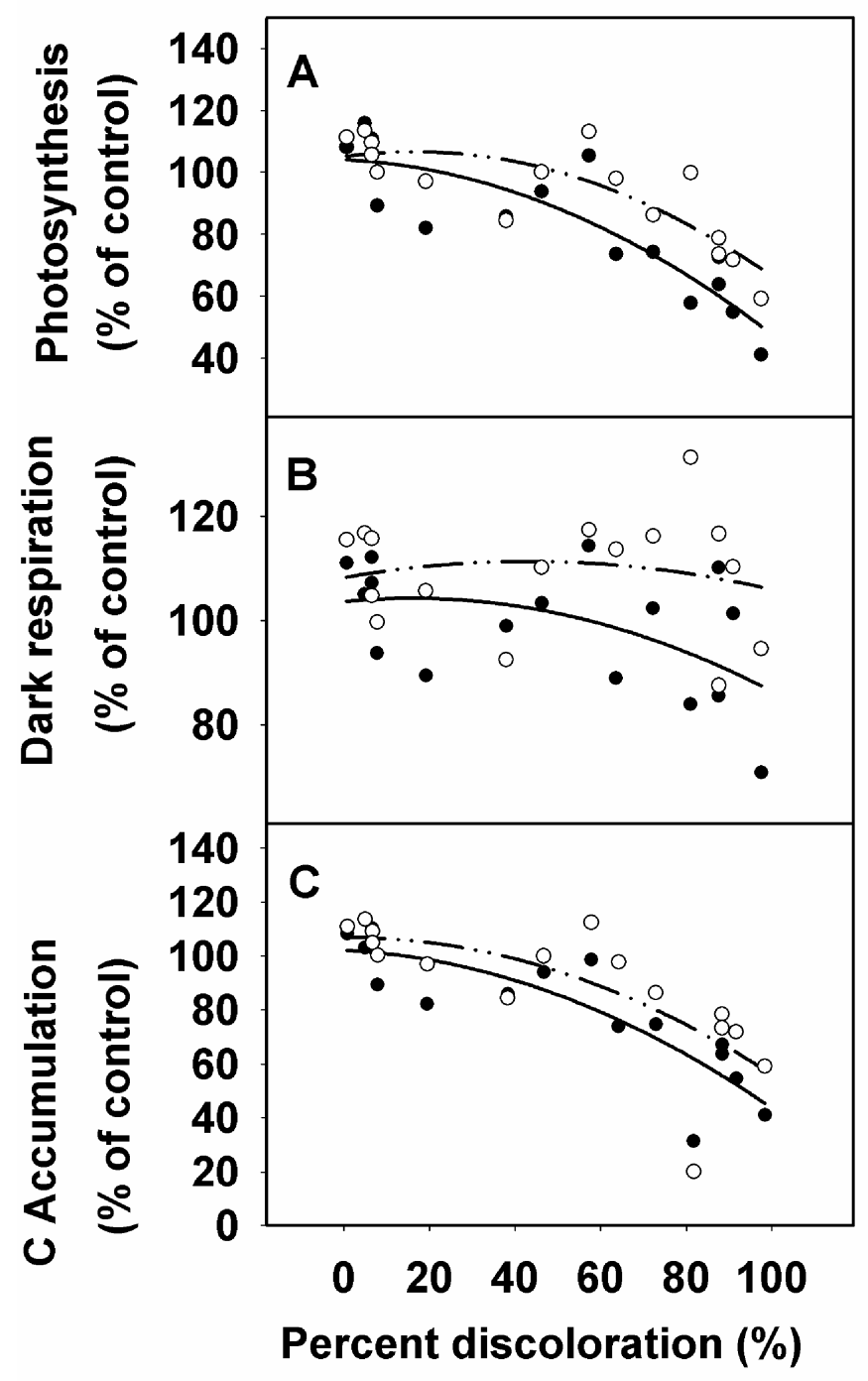

Fig. 4. A, Whole plant photosynthesis, $\mathbf{B}$, dark respiration rate, and $\mathbf{C}$, daily carbon accumulation in hydroponic pepper plants in relation to estimates of percent root discoloration in pepper plants inoculated with Pythium aphanidermatum. Photosynthetic and respiratory rates were extracted from the data described in Figure 3A and B. Each point represents the mean of the gas exchange calculations of Pythium aphanidermatum-inoculated plants expressed as percentages of control values. Graphs include values from four experimental repetitions. under sufficient water stress to limit leaf expansion, other mechanisms are likely involved. One alternative explanation is that leaf expansion was restricted through the effects of signals transferred from the root system to the leaves, such as via the transpiration stream. The strong transpiration in the inoculated peppers would be expected to allow continuous transfer of such signals.

The possibility that root infection can bring about shifts in acropetal transport of phytohormones or other chemical signals from the roots to the shoots, and alter developmental processes in the leaves, is consistent with several observations reported in the literature. In pepper plants grown in vermiculite and inoculated with $V$. dahliae, it was found that the concentration of $\mathrm{ABA}$ in the xylem sap declined during the first week after inoculation compared with that in noninoculated controls (15). At 20 DAI, the transpiration rates of the inoculated plants were comparable to those of the controls when expressed per unit area of leaf, but significantly lower on a per plant basis. In this study, infection of the roots by $V$. dahliae increased leaf senescence and chlorophyll degradation and decreased leaf conductance and photosynthesis relative to the controls. $P$. ultimum and Pythium group F were reported to produce indole-3-acetic acid (IAA) and tryptophol in culture (33), while cell enlargement and callus production in roots infected by $P$. dissotocum pointed to possible involvement of plant growth regulators in pathogenesis in pepper plants (29). In bentgrass, IAA content of the leaves was about 200 times greater in plants inoculated with $P$. aphanidermatum than in noninoculated plants, indicating that IAA is xylem mobile during pathogenesis (38). Root tips, apparently capable of synthesizing growth regulators, are commonly infected by Pythium spp. which might thus influence production of growth regulators at these sites. Aiken and Smucker (2) argued that root tips can transmit, from the root environment, signals capable of regulating plant growth. Farrar and Jones (13) reviewed evidence that roots exert some control over carbon acquisition from source leaves, thus limiting photosynthate available for new leaf expansion.

Growth of leaf area depends on division and enlargement of the leaf cells. Division of leaf cells is limited especially by the supply of photoassimilates and is not markedly affected by availability of water and nutrients (24). Cell expansion, however, is directly related to turgor pressure and dependent upon the availability of water and solutes but is relatively insensitive to the availability of photoassimilates. Given that water movement was not impaired in the inoculated pepper plants, the observed reduction in leaf area

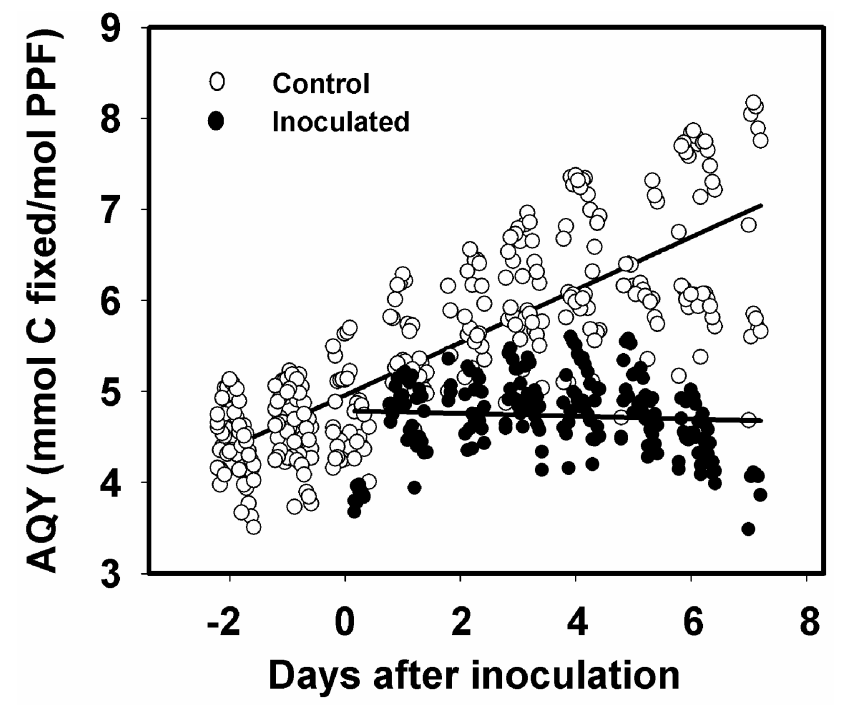

Fig. 5. Apparent quantum yield of hydroponic pepper plants following inoculation with Pythium aphanidermatum. Each point represents an hourly integral from one gas exchange chamber. The experiment was performed four times; results from one representative experiment are shown. 
expansion was probably related to limited availability of photoassimilates. Because the rate of photosynthesis per unit leaf area in our peppers was generally unaffected in the inoculated plants until about 5 DAI ( $t$ test, $P=0.0001$ ), a limited availability of photoassimilates to support division of leaf cells might be expected to have arisen from increased sink strength for photoassimilates elsewhere in our pepper plants. Patterns of relative sink strength and nutrient allocation are recognized as important factors influencing the rate of development and expansion of leaves (41).

A reduced availability of photoassimilates for leaf growth in the inoculated plants could have arisen from strong sink development in the infected roots. Factors contributing to increased sink strength of the infected roots could include demands by the pathogen and any other microbes associated with the roots, increased exudation of carbon compounds into the nutrient solution, energy demands for production of defense compounds by root cells (19), and overall increased metabolism. Observations in the inoculated peppers that whole-plant dark respiration rates were higher than those in the control plants, even though the infected plants were smaller than the controls, were consistent with the view that demand for photoassimilates in diseased roots was high.

We know of no published reports on demands of Pythium spp. for host carbohydrates, but other pathogens are known to utilize simple sugars from the host $(36,40)$. Phytophthora palmivora hydrolyses sucrose extracellularly and takes up glucose and fructose in vitro (37). Increased partitioning of photoassimilates was observed in mycorrhizal clover roots (44). Given that infection by $P$. aphanidermatum involves a biotrophic phase, it is possible that initial colonization involves considerable sink strength. This possibility, and the intriguing prospect that new chemical signals may be transported acropetally from the diseased root systems to the competing shoot system via the xylem stream, remains to be investigated.

In summary, the extent to which changes in photosynthetic behavior of a leaf canopy can be used to monitor disease progress in plants depends greatly upon the parameters measured and the manner in which photosynthetic behavior is expressed. Although leaf photosynthesis may not be affected when expressed on a per area basis, there can be little doubt that reduced canopy photosynthesis in pepper plants infected by $P$. aphanidermatum is largely a consequence of reduced leaf area development. As pointed out by other studies on photosynthesis, to relate photosynthesis to growth, it is necessary to integrate $\mathrm{CO}_{2}$ assimilation over the photoperiod (12). Our data clearly show that the control plants, in which leaf development continued throughout the experimental period, were more efficient in trapping available overhead radiation than the smaller leaf canopy of the inoculated plants. In addition, our data predict that photosynthetic signatures other than $\mathrm{CO}_{2}$ uptake of the young or older leaves may provide signals of progression of Pythium infection; however, more research is required to test this hypothesis. Future research into leaf turnover, export, and partitioning of fixed $\mathrm{C}$ in plants infected with $P$. aphanidermatum is also warranted, as are investigations into the nature of signals moving from the roots to the shoots that might contribute to our understanding of reduced leaf development during infection.

\section{ACKNOWLEDGMENTS}

This research was supported by the Natural Sciences and Engineering Research Council of Canada (Strategic Projects Grant), the Ontario Ministry of Agriculture and Food, Flowers Canada (Ontario) Inc., the Canadian Agricultural Adaptation Council (CanAdapt), and the Centre for Research in Earth and Space Technology. We thank R. Cloutier, D. Leonardos, N. Ortiz, C. Sopher, M. Iqbal, and W. Liu for constructive discussions and technical contributions.

\section{LITERATURE CITED}

1. Aguirreolea, J., Irigoyen, J., Sánchez-Díaz, M., and Salaverri, J. 1995. Physiological alterations in pepper during wilt induced by Phytophthora capsici and soil water deficit. Plant Pathol. 44:587-596.

2. Aiken, R. M., and Smucker, A. J. M. 1996. Root system regulation of whole plant growth. Annu. Rev. Phytopathol. 34:325-346.

3. Ayres, P. 1981. Responses of stomata to pathogenic organisms. Pages 205-221 in: Stomatal Physiology. P. G. Jarvis and T. A. Mansfield, eds. Soc. Exp. Biol. Seminar Series 8, Cambridge University Press, Cambridge, U.K.

4. Bates, M. L., and Stanghellini, M. E. 1984. Root rot of hydroponically grown spinach caused by Pythium aphanidermatum and $P$. dissotocum. Plant Dis. 68:989-991.

5. Bowden, R., and Rouse, D. 1991. Effects of Verticillium dahliae on gas exchange of potato. Phytopathology 81:293-301.

6. Bowden, R., and Rouse, D. 1991. Chronology of gas exchange effects and growth effects of infection by Verticillium dahliae in potato. Phytopathology 81:301-310.

7. Bowden, R. L., Rouse, D. I., and Sharkey, T. D. 1990. Mechanism of photosynthesis decrease by Verticillium dahliae in potato. Plant Physiol. 94:1048-1055.

8. Bugbee, B., and Monje, O. 1992. The limits of crop productivity: Validating theoretical estimates and determining the factors that limit crop yields in optimal environments. Bioscience 42:494-502.

9. Chellemi, D. O., Mitchell, D. J., Kannwischer-Mitchell, M. E., Rayside, P. A., and Rosskopf, E. N. 2000. Pythium spp. associated with bell pepper production in Florida. Plant Dis. 84:1271-1271.

10. Duniway, J., and Slatyer, R. 1971. Gas exchange studies on the transpiration and photosynthesis of tomato leaves affected by Fusarium oxysporum f. sp. lycopersici. Phytopathology 61:1377-1381.

11. Dutton, R. G., Jiao, J., Tsujita, M. J., and Grodzinski, B. 1988. Whole plant $\mathrm{CO}_{2}$ exchange measurements for nondestructive estimation of growth. Plant Physiol. 86:355-358.

12. Evans, J. R. 1998. Photosynthetic characteristics of fast- and slowgrowing species. Pages 101-119 in: Inherent Variation in Plant Growth: Physiological Mechanisms and Ecological Consequences. H. Lambers, H. Poorter, and M. M. I. Van Vuuren, eds. Backhuys Publishers, Leiden, The Netherlands.

13. Farrar, J. F., and Jones, D. L. 2000. The control of carbon acquisition by roots. New Phytol. 147:43-53.

14. Gent, M. P., Ferrandino, F. J., and Elmer, W. H. 1995. Effect of verticillium wilt on gas exchange of entire eggplants. Can. J. Bot. 73:557-565.

15. Goicoechea, N., Aguirreolea, J., Cenoz, S., and García-Mina, J. M. 2000. Verticillium dahliae modifies the concentrations of proline, soluble sugars, starch, soluble protein and abscisic acid in pepper plants. Eur. J. Plant Pathol. 106:19-25.

16. Goicoechea, N., Aguirreolea, J., Cenoz, S., and García-Mina, J. M. 2001. Gas exchange and flowering in Verticillium-wilted pepper plants. J. Phytopathol. 149:281-286.

17. Hall, R., Ali, A., and Busch, L. V. 1975. Verticillium wilt of chrysanthemum: Development of wilt in relation to leaf diffusive resistance and vascular conductivity. Can. J. Bot. 53:1200-1205.

18. Haverkort, A., Rouse, D., and Turkensteen, L. 1990. The influence of Verticillium dahliae and drought on potato crop growth. 1. Effects on gas exchange and stomatal behaviour of individual leaves and crop canopies. Neth. J. Plant Pathol. 96:273-289.

19. Hoffland, E., Jeger, M. J., and Van Beusichem, M. L. 1998. Is plant growth related to disease resistance? Pages 409-427 in: Inherent Variation in Plant Growth: Physiological Mechanisms and Ecological Consequences. H. Lambers, H. Poorter, and M. M. I. Van Vuuren, eds. Backhuys Publishers, Leiden, The Netherlands.

20. Huang, R., and Jarvis, W. R. 2002. Greenhouse crop losses: Disease. Pages 348-352 in: Encyclopedia of Pest Management. D. Pimental, ed. Marcel Dekker, New York.

21. Jeffers, S. N., and Martin, S. B. 1986. Comparison of two media selective for Phytophthora and Pythium species. Plant Dis. 70:1038-1043.

22. Jiao, J., Leonardos, E. D., and Grodzinski, B. 1997. Approaches to Measuring Plant Bioproductivity and Growth. Pages 699-704 in: Handbook of Photosynthesis. M. Pessarakli, ed. Marcel Dekker, New York.

23. Khan, A., Sutton, J. C., and Grodzinski, B. 2003. Effects of Pseudomonas chlororaphis on Pythium aphanidermatum and root rot in peppers grown in small-scale hydroponic troughs. Biocontrol Sci. Technol. 13:615-630.

24. Kriedemann, P. E. 1986. Stomatal and photosynthetic limitations to leaf growth. Aust. J. Plant Physiol. 13:15-31.

25. Leonardos, E. D., Tsujita, M. J., and Grodzinski, B. 1994. Net carbon dioxide exchange rates and predicted growth patterns in Alstroemeria 'Jacqueline' at varying irradiances, carbon dioxide concentrations and air temperatures. J. Am. Soc. Hortic. Sci. 119:1265-1275. 
26. Lorenzini, G., Guidi, L., Nali, C., Ciompi, S., and Soldatini, G. F. 1997. Photosynthetic response of tomato plants to vascular wilt diseases. Plant Sci. 124:143-152.

27. MacHardy, W. E., Busch, L. V., and Hall, R. 1976. Verticillium wilt of chrysanthemum: Quantitative relationship between increased stomatal resistance and local vascular dysfunction preceding wilt. Can. J. Bot. 54:1023-1034.

28. Owen-Going, T. N. 2002. Etiology and epidemiology of Pythium root-rot in bell pepper (Capsicum annuum L.) in commercial-scale and smallscale hydroponic systems. M.S. thesis. University of Guelph, Ontario, Canada.

29. Owen-Going, T. N., Sutton, J. C., and Grodzinski, B. 2003. Relationships of Pythium isolates and sweet pepper plants in single-plant hydroponic units. Can. J. Plant Pathol. 25:155-167.

30. Pennypacker, B. W., Knievel, D. P., Leath, K. T., Pell, E. J., and Hill, R. R., Jr. 1990. Analysis of photosynthesis in resistant and susceptible alfalfa clones infected with Verticillium albo-atrum. Phytopathology 80:13001306.

31. Ploetz, R., and Schaffer, B. 1989. Effects of flooding and Phytophthora root rot on net gas exchange and growth of avocado. Phytopathology 79:204-208.

32. Rahimian, M. K., and Banihashemi, Z. 1979. A method for obtaining zoospores of Pythium aphanidermatum and their use in determining cucumber seedling resistance to damping-off. Plant Dis. Rep. 63:658661.

33. Rey, P., Leucart, S., Désilets, H., Bélanger, R. R., Larue, J. P., and Tirilly, Y. 2001. Production of indole-3-acetic acid and tryptophol by Pythium ultimum and Pythium group F: Possible role in pathogenesis. Eur. J. Plant Pathol. 107:895-904.

34. Saeed, I. A., MacGuidwin, A. E., Rouse, D. I., and Sharkey, T. D. 1999. Limitation to photosynthesis in Pratylenchus penetrans- and Verticillium dahliae-infected potato. Crop Sci. 39:1340-1346.

35. Sánchez, J., Olivares, J. S., and Gallego, E. 2001. Occurrence and pathogenicity of five Pythium spp. in the dust deposited on the greenhouse roofs in the Poniente region of Almeria (South-east Spain). J. Plant Pathol. 83:13-19.

36. Scholes, J. D., Lee, P. J., Horton, P., and Lewis, D. H. 1994. Invertase: Understanding changes in the photosynthetic and carbohydrate metabolism of barley leaves infected with powdery mildew. New Phytol. 126:213-222.

37. Sheard, J., and Farrar, J. F. 1987. Transport of sugar in Phytophthora palmivora (Butl.) Butl. New Phytol. 105:265-272.

38. Shimada, A., Takeuchi, S., Nakajima, A., Tanaka, S., Kawano, T., and Kimura, Y. 1999. Phytotoxicity of indole-3-acetic acid produced by the fungus, Pythium aphanidermatum. Biosci. Biotechnol. Biochem. 63:187189.

39. Stanghellini, M. E., and Kronland, W. C. 1986. Yield loss in hydroponically grown lettuce attributed to subclinical infection of feeder rootlets by Pythium dissotocum. Plant Dis. 70:1053-1056.

40. Sutton, P. N., Henry, M. J., and Hall, J. L. 1999. Glucose, and not sucrose, is transported from wheat to wheat powdery mildew. Planta 208:426-430.

41. Van Volkenburgh, E., Stahlberg, R., and Bultynck, L. 1998. Physiological mechanisms controlling the rate of leaf growth. Pages 41-56 in: Inherent Variation in Plant Growth: Physiological Mechanisms and Ecological Consequences. H. Lambers, H. Poorter, and M. M. I. Van Vuuren, eds. Backhuys Publishers, Leiden, The Netherlands.

42. Waters, G. C. R., Gidzinski, D., Zheng, Y., Stasiak, M., and Dixon, M. 2003. SAE Technical Series 2003-01-2359. Society of Automotive Engineers International.

43. Woodrow, L., Thompson, R. G., and Grodzinski, B. 1988. Effects of ethylene on photosynthesis and partitioning in tomato, Lycopersicon esculentum Mill. J. Exp. Bot. 39:667-684.

44. Wright, D. P., Read, D. J., and Scholes, J. D. 1998. Mycorrhizal sink strength influences whole plant carbon balance of Trifolium repens L. Plant Cell Environ. 21:881-891.

45. Zheng, J., Sutton, J. C., and Yu, H. 2000. Interactions among Pythium aphanidermatum, roots, root mucilage, and microbial agents in hydroponic cucumbers. Can. J. Plant Pathol. 22:368-379. 